\title{
Does Obesity Affect the Ocular Choroid Tissue in Children and Adolescents?
}

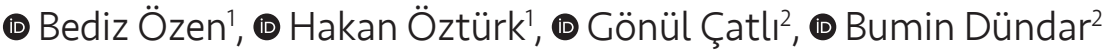 \\ 'University of Health Sciences, İzmir Tepecik Training and Research Hospital, Clinic of Ophthalmology, İzmir, Turkey \\ ${ }^{2}$ Izmir Katip Çelebi University Faculty of Medicine, Department of Pediatric Endocrinology, İzmir, Turkey
}

\begin{abstract}
Aim: Obesity may cause microangiopathic changes associated with the inflammatory process. The choroid tissue of the eye is one of the most highly vascularized tissues of body and supplies the outer $1 / 3$ of the retina. Thinning in choroid tissue is an indicator of damage. Few studies have investigated obesity-induced choroid tissue damage in children, and their findings are inconsistent. The purpose of this study was to investigate changes in choroid tissue thickness in non-diabetic children and adolescents using optic coherence tomography (OCT) and the association with metabolic risk factors. Materials and Methods: One hundred fifty-six eyes of 38 obese and 40 healthy children and adolescents aged 10-18 were included in the study. The bilateral choroidal thicknesses were measured. We then investigated correlations between choroidal thickness and age, body measurements, pubertal stages, systolic and diastolic blood pressures, homeostasis model assessment insulin resistance and lipid values.

Results: Mean choroidal thicknesses measured using OCT were $284.4 \pm 34.9 \mu \mathrm{m}$ in the obese group and $316.3 \pm 39.7 \mu \mathrm{m}$ in the control group ( $p=0.018$ ). Choroidal thickness in the obese group decreased as body mass index (BMI) standard deviation scores (SDS) increased $(r=-0.390, p=0.000)$.

Conclusion: Mean choroidal thickness was lower in obese children and adolescents in this study compared to the healthy controls and thinning in the choroid tissue was more pronounced as BMI-SDS values increased. Increased adipose tissue may result in a susceptibility to damage by thinning choroid tissue.

Keywords: Choroidal thickness, optical coherence tomography, pediatric obesity
\end{abstract}

\section{Introduction}

The prevalence of childhood obesity is growing. Obesity may cause microangiopathic changes associated with the inflammatory process $(1,2)$. Microvascular changes caused by obesity may result in damage to the optic nerve, retinal nerve fiber layer (RNFL) and choroidal regions, and damage can be revealed in the early period with optic coherence tomography (OCT). The layers of the eye can be visualized in a painless, rapid and non-invasive way using OCT (3). The choroid is one of the most highly vascularized tissues of body and it supplies the outer $1 / 3$ of the retina. The choroid also plays important anatomical and physiological roles, including ocular thermoregulation, the regulation of intraocular pressure and growth factor secretion. Thinning of choroid tissue is a damage indicator $(4,5)$. Previous studies have investigated choroidal thickness in healthy children (6-9). However, few studies have investigated the effect on choroidal and retinal structure in obese children, and their results are inconsistent. The purpose of this study was to investigate changes in choroid tissue thickness in non-diabetic children and adolescents using OCT and the association with metabolic risk factors and pubertal stages.

\section{Address for Correspondence}

Bediz Özen MD, University of Health Sciences, Izmir Tepecik Training and Research Hospital, Clinic of Ophthalmology, Izmir, Turkey Phone: +90 2324696969 E-mail: bedizozen@yahoo.com ORCID ID: orcid.org/0000-0001-9020-3810

Received: 17.03.2018 Accepted: 24.03.2018

${ }^{\circ}$ Copyright 2018 by Ege University Faculty of Medicine, Department of Pediatrics and Ege Children's Foundation The Journal of Pediatric Research, published by Galenos Publishing House. 


\section{Materials and Methods}

Consent form was filled out by all participants. The study was approved by the Izmir Tepecik Training and Research Hospital Local Ethics Committee (approval number: 29.12.2014/20). All procedures were conducted in line with the ethical principles of the Declaration of Helsinki.

Inclusion criteria for study and control subjects:

- Age 10-18 years

- No neurological diseases

- No history of ocular disease or surgery

- Children and parents being compliant with examinations

- Subjects with spherical values between -0.50 D and +0.50 D were enrolled.

Exclusion criteria for study and control subjects:

- Presence of diabetes mellitus or any systemic disease

- Use of systemic corticosteroids

- Non-compliance with OCT measurement

- History of ocular trauma and dense media opacities

Seventy-six eyes of 38 obese children and adolescents aged 10.1-17.2 years presenting to the İzmir Tepecik Training and Research Hospital Pediatric Endocrinology Clinic, Turkey, between January 2015 and May 2016, and 80 eyes of 40 healthy children and adolescents aged 10.2-18.0 years were included in the study. The demographic characteristics of the obese and control groups were recorded from their medical files. Body measurements, blood pressure values and pubertal stages were assessed by an experienced pediatric endocrinologist. Pubertal stages were classified based on Tanner's system (10). Height was measured to the nearest centimeter using a rigid stadiometer. Weight was measured to the nearest $0.1 \mathrm{~kg}$ using a calibrated balance scale with the subject unclothed. Body mass index (BMI) was determined using the formula weight $(\mathrm{kg}) /$ height squared $\left(\mathrm{m}^{2}\right)$. Established reference values for Turkish children were employed to calculate the standard deviation scores (SDS) for weight, height and BMI (11). Obesity was diagnosed on the basis of World Health Organization definitions (12). Blood pressure was measured in all cases following a period of rest. Measurements were taken at least three times at 10-minute intervals. Individuals with systolic and/or diastolic blood pressure values greater than the $95^{\text {th }}$ percentile were considered hypertensive (13). Blood glucose, insulin and serum lipids in the case of obese subjects were measured using an automatic analyzer from fasting venous specimens collected on that day. Insulin resistance using the homeostasis model assessment insulin resistance (HOMA-IR) was calculated using the formula fasting insulin $(\mu \mathrm{lU} / \mathrm{mL}) \times$ fasting glucose $(\mathrm{mg} / \mathrm{dL}) / 405$ (14). All cases underwent detailed eye examinations performed by the same ophthalmologist. Best corrected visual acuities were measured, detailed anterior segment examination was performed with a slit-lamp biomicroscope, intraocular pressure measurement using Goldman applanation tonometry, ocular motility evaluation and optic nerve and retinal examination with a 90 dioptric lens. For pupil dilation, 1\% cyclopentolate hydrochloride (Sikloplejin R; Abdi Ibrahim İaç Sanayi, İstanbul) eye drops were applied twice at 5 min intervals, and the mean of three measurements performed 30 min after the final application using an autorefractometer (Canon RK-F1) was taken. Ocular biometry was measured by the LenStar biometer (Haag-Streit, Switzerland)

Choroidal thickness was measured manually using OCT (Heidelberg Spectralis, Heidelberg Engineering, Heidelberg, Germany) in increased imaging depth mode in order to optimize choroidal resolution. Automatic real time eye tracking was performed. Choroidal thickness was measured between the outer border of the hyper-reflective retinal pigment epithelium and the inner border of the choroidalscleral junction. Measurements were performed bilaterally by two independent masked observers. Choroidal thicknesses were measured using OCT, $500 \mu \mathrm{m}$ nasal (N500) and 500 $\mu \mathrm{m}$ temporal (T500) from the foveal center (C). Mean choroidal thickness values were recorded. All OCT imaging was performed between 09.00 and 11.00 in order to avoid diurnal variation. Statistical analysis was performed using the choroidal thickness values measured and the mean thereof. Choroidal thicknesses were compared between the control and obese groups. We then investigated correlations between choroidal thickness and age, pubertal stages, body measurements, systolic and diastolic blood pressures, fasting insulin, HOMA-IR and lipid values.

\section{Statistical Analysis}

Statistical Package for Social Sciences (SPSS 20.0; IBM, USA) software was employed for statistical analyses. The Kolmogorov-Smirnov test was used to evaluate the normality of the sample distribution. Mean and standard deviation values are provided for all parameters. Pearson correlation analysis was used to assess relations for normally distributed variables. Spearman correlation analysis was applied to non-normally distributed variables. A value of $p<0.05$ was considered statistically significant.

\section{Results}

Mean ages were $12.8 \pm 2.1$ years in the obese group $(n=38)$ and $12.9 \pm 2.4$ in the control group $(n=40)$. The difference between the two groups was not statistically significant $(p=0.99)$. Also, no significant difference was determined between the two groups in terms of sex distributions, pubertal stages or mean systolic and diastolic blood pressures. BMISDS was $3.0 \pm 0.4$ in the obese group compared to $0.5 \pm 0.4$ in the control group $(p<0.0001)$. Fasting blood glucose values were within normal limits in both groups (control group: $82.1 \pm 8.8 \mathrm{mg} / \mathrm{dL}$, obese group: $85.3 \pm 9.9 \mathrm{mg} / \mathrm{dL}, \mathrm{p}=0.65)$. As anticipated, morning fasting insulin and HOMA-IR values were statistically significantly higher in the obese 
individuals compared to the controls (obese group fasting insulin: 19.6 \pm 9.8 , control group fasting insulin: $8.3 \pm 3.1 \mathrm{mIU} /$ $\mathrm{mL}, \mathrm{p}=0.02$, obese group HOMA-IR: $4.7 \pm 2.7$, control group HOMA-IR: $1.9 \pm 0.7, p=0.01$ ). There was no difference between the two groups in terms of serum lipid levels. Clinical and laboratory characteristics of the obese and control groups are shown in Table I. Between the axial length measurement in study $(22.7 \pm 0.6 \mathrm{~mm})$ and control $(22.8 \pm 0.5)$ groups, there was no statistically significant difference $(p=0.211)$. No statistically significant difference was determined between sex and both eyes in terms of choroidal thickness values measured using OCT $(p=0.81)$. When the central, nasal and temporal quadrants were assessed individually in terms of choroidal thicknesses, choroidal thinning was observed in all quadrants in the obese group compared to the controls, but the difference was not statistically significant. However, mean choroidal thickness values were $284.4 \pm 34.9 \mu \mathrm{m}$ (range, 230-378 $\mu \mathrm{m}$ ) in the obese group and $316.3 \pm 39.7 \mu \mathrm{m}$ (range $293-348 \mu \mathrm{m}$ ) in the control group. This difference was statistically significant $(p=0.018)$. Choroidal thickness values in the study groups are shown in Table II. The relations between clinical and laboratory variables and choroidal thickness were analysed. Age and pubertal stage were positively correlated with choroidal thickness, although no statistical significance was determined ( $p>0.05$ ). No correlation was determined between choroidal thickness and blood pressure, serum fasting glucose, HOMA-IR or lipid levels. In the obese group, choroidal thickness decreased as BMI-SDS values increased $(r=-0.390, p<0.0001)$. In the control

\begin{tabular}{|c|c|c|c|}
\hline $\begin{array}{l}\text { Clinical or laboratory } \\
\text { characteristics }\end{array}$ & $\begin{array}{l}\text { Control } \\
(n=40)\end{array}$ & $\begin{array}{l}\text { Obese } \\
(n=38)\end{array}$ & p value ${ }^{a}$ \\
\hline Gender (male/female) & $21 / 19$ & $18 / 20$ & $0.81^{\mathrm{b}}$ \\
\hline Age (years) & $12.9 \pm 2.4$ & $12.8 \pm 2.1$ & 0.99 \\
\hline $\begin{array}{l}\text { Puberty stage (pre-pubertal/ } \\
\text { pubertal) }\end{array}$ & $11 / 29$ & $10 / 28$ & $0.98^{b}$ \\
\hline BMI-SDS & $0.5 \pm 0.4$ & $3.0 \pm 0.4$ & 0.000 \\
\hline Systolic BP (mmHg) & $106.1 \pm 9.1$ & $111.8 \pm 9.4$ & 0.19 \\
\hline Diastolic BP (mmHg) & $66.3 \pm 6.7$ & $69.2 \pm 9.3$ & 0.28 \\
\hline Fasting glucose (mg/dL) & $82.1 \pm 8.8$ & $85.3 \pm 9.9$ & 0.65 \\
\hline Fasting insuline (mIU/mL) & $8.3 \pm 3.1$ & $19.6 \pm 9.8$ & 0.02 \\
\hline HOMA-IR & $1.9 \pm 0.7$ & $4.7 \pm 2.7$ & 0.01 \\
\hline Triglycerides (mg/dL) & $125.3 \pm 62.0$ & $138.5 \pm 72.9$ & 0.07 \\
\hline LDL-cholesterol (mg/dL) & $89.3 \pm 18.6$ & $96.9 \pm 25.7$ & 0.06 \\
\hline HDL-cholesterol (mg/dL) & $46.1 \pm 11.3$ & $43.2 \pm 10.3$ & 0.72 \\
\hline
\end{tabular}

aStudent's $T$ test, ${ }^{\circ}$ Chi-square test

BMI-SDS: Body mass index-standard deviation score, BP: Blood pressure, HDL: High density lipoprotein, HOMA-IR: Homeostasis model assessment of insulin resistance, LDL: Low density lipoprotein group, although negative correlation was observed between increasing $\mathrm{BMI}$ and choroidal thickness, this correlation was not statistically significant $(r=-0.112, p=0.079)$. Pearson correlation analysis results between choroidal thickness and clinical and laboratory data are shown in Table III.

\section{Discussion}

The choroid, one of the most highly vascularized tissues in the body, is particularly susceptible to diseases leading to microvascular complications. Like other ocular structures, choroidal thickness may vary throughout childhood. Examination of choroidal thickness provides important information in the diagnosis and management of various ocular and systemic diseases leading to chorioretinal inflammatory changes $(4,15)$. Previous studies have shown choroidal thinning independent of stage of retinopathy in Type II diabetes (16). Lower choroidal thickness has also been observed compared to healthy controls in several diseases, such as hypertension, rheumatoid arthritis, systemic lupus

\begin{tabular}{|l|l|l|l|}
\hline \multicolumn{4}{|l|}{ Table II. Choroidal thickness in control and obese children } \\
\hline Choroidal thickness & $\begin{array}{l}\text { Control } \\
(\mathbf{n = 4 0 )}\end{array}$ & $\begin{array}{l}\text { Obese } \\
(\mathbf{n = 3 8 )}\end{array}$ & p value \\
\hline Central $(\mathrm{C})(\mu \mathrm{m})$ & $320.5 \pm 40.0$ & $288.5 \pm 35.0$ & 0.112 \\
\hline Nasal $(\mathrm{N} 500)(\mu \mathrm{m})$ & $303.5 \pm 39.1$ & $271.4 \pm 34.6$ & 0.068 \\
\hline Temporal $(\mathrm{T500})(\mu \mathrm{m})$ & $325.1 \pm 40.0$ & $293.4 \pm 35.1$ & 0.082 \\
\hline Avarage $(\mu \mathrm{m})$ & $316.3 \pm 39.7$ & $284.4 \pm 34.9$ & 0.018 \\
\hline
\end{tabular}

Table III. Correlation analysis of choroidal thickness with the clinical and laboratory parameters of the study groups

\begin{tabular}{|l|l|l|l|l|}
\hline & \multicolumn{2}{|l|}{ Control } & \multicolumn{2}{l|}{ Obese } \\
\hline $\begin{array}{l}\text { Clinical or laboratory } \\
\text { characteristics }\end{array}$ & $\boldsymbol{r}$ & $\boldsymbol{p}$ value & $\mathbf{r}$ & $\boldsymbol{p}$ value \\
\hline Age & 0.161 & 0.157 & 0.197 & 0.099 \\
\hline Puberty stage & 0.142 & 0.214 & 0.156 & 0.116 \\
\hline BMI-SDS & -0.112 & 0.079 & -0.390 & 0.000 \\
\hline Systolic BP & -0.159 & 0.164 & -0.165 & 0.570 \\
\hline Diastolic BP & -0.145 & 0.209 & -0.166 & 0.124 \\
\hline Fasting glucose & 0.029 & 0.227 & 0.155 & 0.308 \\
\hline Fasting insulin & 0.077 & 0.566 & 0.172 & 0.093 \\
\hline HOMA-IR & 0.211 & 0.099 & 0.290 & 0.059 \\
\hline Triglycerides & 0.014 & 0.731 & 0.189 & 0.231 \\
\hline LDL-cholesterol & 0.073 & 0.632 & -0.174 & 0.210 \\
\hline HDL-cholesterol & 0.056 & 0.755 & 0.094 & 0.178 \\
\hline
\end{tabular}

BMI-SDS: Body mass index-standard deviation score, BP: Blood pressure, HDL: High density lipoprotein, HOMA-IR: Homeostasis model assessment of insulin resistance, LDL: Low density lipoprotein 
erythematosus, and obstructive sleep apnoea (17-20). Chronic microvascular systemic inflammation is implicated in the development of all these diseases. Obesity and severe obesity have become an increasingly severe public health problem in children in recent years $(21,22)$. Obesity can lead to systemic and ocular complications. The RNFL and the thickness of choroid tissue can be affected by obesity. Previous studies have shown that obesity causes a thinning in RNFL thickness in children $(23,24)$. Low level systemic inflammation is known to occur in obesity (25-27). For may also have the potential to affect the choroid layer. Previous studies have reported normative data concerning choroidal thicknesses in healthy children and adolescents. Read et al. (6) reported a mean subfoveal choroidal thickness of $330 \pm 65 \mathrm{~mm}$ (range, 189$538 \mathrm{~mm}$ ) in 194 healthy children aged 4-12. In addition, they determined normal choroidal thicknesses of $312 \pm 62 \mathrm{~mm}$ at age $4-6,337 \pm 65 \mathrm{~mm}$ at age $7-9$, and $341 \pm 61 \mathrm{~mm}$ at age 10-12. Based on these findings, they reported that choroidal thickness increases from early childhood. We also determined a positive correlation, although not at a statistically significant level, between age and pubertal stage and choroidal thickness. In The Copenhagen Child Cohort 2000 Eye Study of 1323 children aged 11-12, Li et al. (7) determined a mean subfoveal choroidal thickness of $369 \pm 81 \mathrm{~mm}$, but determined no relation between choroidal thickness and sex. We also observed no significant difference between the sexes in terms of choroidal thickness values ( $p>0.05)$. Bidaut-Garnier et al. (8) measured a mean subfoveal choroidal thickness of $341.96 \pm 74.7 \mathrm{~mm}$ and reported that the choroid was thinner in the nasal region than in the temporal region. In their study of healthy children under 18, Lee et al. (9) determined greater choroidal thicknesses in the macular region in all quadrants investigated compared to adults. They also emphasized that pediatric subfoveal choroidal thickness is disposed to thinning with age and refractive error. Subjects with refractive error were excluded from our study. The mean choroidal thickness measured with OCT in the healthy children and adolescents we enrolled as the control group was 316.3 \pm 39.7 $\mu \mathrm{m}$. These values are in agreement with previous studies. Few studies have investigated choroidal thickness in obese children, and their findings are inconsistent. In their study of obese children aged 5-15, Erşan et al. (28) determined a mean choroidal thickness of $301.95 \pm 56.72 \mathrm{~mm}$ in the control group and of $270.20 \pm 56.13 \mathrm{~mm}$ in the obese group ( $p=0.014)$. They reported that this thinning might be due to microvascular complication. In contrast to that study, Bulus et al. (29) reported a mean choroidal thickness of $348.43 \pm 73.21 \mathrm{~mm}$ in the control group and of $385.77 \pm 6.09 \mathrm{~mm}$ in obese children. Choroidal thickness increased in the obese group $(p=0.017)$. The authors suggested that choroidal thickening might be attributed to obesity-related vascular changes and increased adipocyte tissue. We observed thinning of choroidal thickness in all the measured quadrants in obese children compared to the healthy controls. Mean choroidal thicknesses were $316.3 \pm 39.7 \mu \mathrm{m}$ (range 293-378 $\mu \mathrm{m}$ ) in the control group and $284.4 \pm 34.9$ (range, 230-360 $\mu \mathrm{m}$ ) in the obese group. This difference in choroidal thicknesses was statistically significant $(p=0.018)$. Thinning in choroidal thickness in obese cases may be associated with chronic systemic inflammation and microvascular disturbance (25-27). Oxidative stress and hypoxia may occur in obesity. In addition, changes in leptin and adipokines levels, adipose tissue dysfunction and insulin resistance may also occur. The production of inflammatory cytokines and reactive oxygen species increases due to the oxidative stress. Apoptosis and tissue necrosis are then triggered as a result. Studies have shown that oxidative stress may be a significant factor in cell death (30-33). Vascular endothelial damage, oxidative stress and chronic inflammation may impair the permeability and nutrition of microvascular structures. This may then give rise to thinning of choroid tissue. Choroidal thickness measurement may be affected by diurnal variation. We performed our measurements at the same time interval, between 09.00 and 11.00, in order to avoid diurnal fluctuation. The border of the chorioscleral junction was measured manually. Choroid OCT images were taken by two independent masked observers. Studies concerning the reliability and repeatability of this manual measurement method have reported powerful correlation between measurements and the individuals performing them (34-36). There are a number of limitations to this study. Plasma levels of inflammatory mediators such as adiponectin, leptin and interleukin-6 could not be measured. However, the metabolic and vascular effects of these mediators were evaluated indirectly by measuring insulin, lipid and glucose levels. No studies have shown whether changes in choroidal thickness values will occur through weight loss in obese individuals. Prospective observational studies involving weight control are needed in order to reveal more clearly the effect of obesity, and therefore the chronic inflammatory process, on choroidal tissue.

\section{Conclusions}

In conclusion, this study shows a lower mean choroidal tissue thickness in obese children and adolescents compared to healthy controls. In addition, the decrease in choroidal tissue thickness becomes more marked as BMI-SDS values increase. An increase in adipose tissue may result in a susceptibility to retinal damage. Long-term observational studies are now needed in order to confirm the findings of this cross-sectional study.

\section{Ethics}

Ethics Committee Approval: The study was approved by the İzmir Tepecik Training and Research Hospital Local Ethics Committee (approval number: 29.12.2014/20). 
Informed Consent: Consent form was filled out by all participants.

Peer-review: External and internal peer-reviewed.

\section{Authorship Contributions}

Surgical and Medical Practices: B.Ö., H.Ö, Concept: B.Ö., H.Ö, G.Ç., Design: B.Ö., H.Ö, G.Ç., Data Collection or Processing: B.Ö., H.Ö, G.Ç., Analysis or Interpretation: B.Ö., H.Ö, G.Ç., B.D., Literature Search: B.Ö., H.Ö, G.Ç., B.D., Writing: B.Ö., H.Ö, G.Ç.

Conflict of Interest: No conflict of interest was declared by the authors.

Financial Disclosure: The authors declared that this study received no financial support.

\section{References}

1. Sabin MA, Kiess W. Childhood obesity: Current and novel approaches. Best Pract Res Clin Endocrinol Metab 2015;29:32738.

2. Lifshitz F. Obesity in children. / Clin Res Pediatr Endocrinol 2008;1:53-60.

3. Galetta KM, Calabresi PA, Frohman EM, Balcer LJ. Optical coherence tomography (OCT): imaging the visual pathway as a model for neurodegeneration. Neurotherapeutics 2011;8:117-32.

4. Nickla DL, Wallman J. The multifunctional choroid. Prog Retin Eye Res 2010;29:144-68.

5. Alm A, Nilsson SF. Uveoscleral outflow--a review. Exp Eye Res 2009;88:760-8.

6. Read SA, Collins MJ, Vincent SJ, Alonso-Caneiro D. Choroidal thickness in childhood. Invest Ophthalmol Vis Sci 2013;54:3586-93.

7. Li XQ, Jeppesen $P$, Larsen M, Munch IC. Subfoveal choroidal thickness in 1323 children aged 11 to 12 years and association with puberty: the Copenhagen Child Cohort 2000 Eye Study. Invest Ophthalmol Vis Sci 2014;55:550-5.

8. Bidaut-Garnier M, Schwartz C, Puyraveau M, Montard M, Delbosc $B$, Saleh M. Choroidal thickness measurement in children using optical coherence tomography. Retina 2014;34:768-74.

9. Lee JW, Song IS, Lee JH, et al. Macular Choroidal Thickness and Volume Measured by Swept-source Optical Coherence Tomography in Healthy Korean Children. Korean I Ophthalmol 2016;30:32-9.

10. Tanner JM, Whitehouse RH. Clinical longitudinal standards for height, weight, height velocity, weight velocity, and stages of puberty. Arch Dis Child 1976;51:170-9.

11. Neyzi O, Bundak R, Gökçay G, et al. Reference Values for Weight, Height, Head Circumference, and Body Mass Index in Turkish Children. J Clin Res Pediatr Endocrinol 2015;7:280-93.

12. WHO Multicentre Growth Reference Study Group. WHO Child Growth Standards: Length/height-for-age, weight-for-age, weight-for-length, weight-for-height and body mass indexfor-age: Methods and development. Geneva: World Health Organization, 2006.

13. Lurbe E, Agabiti-Rosei E, Cruickshank JK, et al. 2016 European Society of Hypertension guidelines for the management of high blood pressure in children and adolescents. I Hypertens 2016;34:1887-920.
14. Keskin M, Kurtoglu S, Kendirci M, Atabek ME, Yazici C. Homeostasis model assessment is more reliable than the fasting glucose/insulin ratio and quantitative insulin sensitivity check index for assessing insulin resistance among obese children and adolescents. Pediatrics 2005;114:500-3.

15. Sezer T, Altınışık M, Koytak IA, Özdemir MH. The Choroid and Optical Coherence Tomography. Turk J Ophthalmol 2016;46:30-7.

16. Unsal E, Eltutar K, Zirtiloğlu S, Dinçer N, Ozdoğan Erkul S, Güngel $\mathrm{H}$. Choroidal thickness in patients with diabetic retinopathy. Clin Ophthalmol 2014;8:637-42.

17. Esmaeelpour M, Považay B, Hermann B, et al. Mapping choroidal and retinal thickness variation in type 2 diabetes using threedimensional 1060-nm optical coherence tomography. Invest Ophthalmol Vis Sci 2011;52:5311-6.

18. Duru N, Altinkaynak H, Erten \$̧, et al. Thinning of Choroidal Thickness in Patients with Rheumatoid Arthritis Unrelated to Disease Activity. Ocul Immunol Inflamm 2016;24:246-53.

19. Akay F, Gundogan FC, Yolcu U, Toyran S, Uzun S. Choroidal thickness in systemic arterial hypertension. Eur / Ophthalmol 2016;26:152-7.

20. Karalezli A, Eroglu FC, Kivanc T, Dogan R. Evaluation of choroidal thickness using spectral-domain optical coherence tomography in patients with severe obstructive sleep apnea syndrome: a comparative study. Int J Ophthalmol 2014;7:1030-4.

21. Sabin MA, Kiess W. Childhood obesity: Current and novel approaches. Best Pract Res Clin Endocrinol Metab 2015;29:327-38.

22. Lifshitz F. Obesity in children. I Clin Res Pediatr Endocrinol 2008;1:53-60.

23. Özen B, Öztürk H, Çatlı G, Dündar B. An Assessment of Retinal Nerve Fiber Layer Thickness in Non-Diabetic Obese Children and Adolescents. J Clin Res Pediatr Endocrinol 2018;10:13-8.

24. Pacheco-Cervera J, Codoñer-Franch P, Simó-Jordá R, PonsVázquez S, Galbis-Estrada C, Pinazo-Durán MD. Reduced retinal nerve fibre layer thickness in children with severe obesity. Pediatr Obes 2015;10:448-53.

25. Karti O, Nalbantoglu O, Abali S, Tunc S, Ozkan B. The assessment of peripapillary retinal nerve fiber layer and macular ganglion cell layer changes in obese children: a cross-sectional study using optical coherence tomography. Int Ophthalmol 2017;37:1031-8.

26. Tsai DC, Huang N, Hwu IJ, Jueng RN, Chou P. Estimating retinal nerve fiber layer thickness in normal schoolchildren with spectral-domain optical coherence tomography. Ipn I Ophthalmol 2012;56:362-70.

27. Barrio-Barrio I, Noval S, Galdós M, et al. Multicenter Spanish study of spectral-domain optical coherence tomography in normal children. Acta Ophthalmol 2013;91:56-63.

28. Erşan I, Battal F, Aylanç H, et al. Noninvasive assessment of the retina and the choroid using enhanced-depth imaging optical coherence tomography shows microvascular impairments in childhood obesity. I AAPOS 2016;20:58-62.

29. Bulus AD, Can ME, Baytaroglu A, Can GD, Cakmak HB, Andiran N. Choroidal Thickness in Childhood Obesity. Ophthalmic Surg Lasers Imaging Retina 2017;48:10-7.

30. Trayhurn P. Hypoxia and adipose tissue function and dysfunction in obesity. Physiol Rev 2013;93:1-21.

31. Norouzirad R, González-Muniesa P, Ghasemi A. Hypoxia in Obesity and Diabetes: Potential Therapeutic Effects of Hyperoxia and Nitrate. Oxid Med Cell Longev 2017;2017:5350267. 
32. Ouchi N, Ohashi K, Shibata R, Murohara T. Adipocytokines and obesity-linked disorders. Nagoya I Med Sci 2012;74:19-30.

33. McMurray F, Patten DA, Harper ME. Reactive Oxygen Species and Oxidative Stress in Obesity-Recent Findings and Empirical Approaches. Obesity (Silver Spring) 2016;24:2301-10.

34. Ikuno Y, Maruko I, Yasuno Y, et al. Reproducibility of retinal and choroidal thickness measurements in enhanced depth imaging and high-penetration optical coherence tomography. Invest Ophthalmol Vis Sci 2011;52:5536-40.
35. Branchini L, Regatieri CV, Flores-Moreno I, Baumann B, Fujimoto JG, Duker JS. Reproducibility of choroidal thickness measurements across three spectral domain optical coherence tomography systems. Ophthalmology 2012;9:119-23.

36. Chhablani 11, Barteselli $\mathrm{G}$, Wang $\mathrm{H}$, et al. Repeatability and reproducibility of manual choroidal volume measurements using enhanced depth imaging optical coherence tomography. Invest Ophthalmol Vis Sci 2012;53:2274-80. 